\title{
Rhizomelic syndrome, Urbach type
}

INSERM

\section{Source}

INSERM. (1999). Orphanet: an online rare disease and orphan drug data base. Rhizomelic syndrome, Urbach type. ORPHA:3098

Rhizomelic syndrome, Urbach type is a rare primary bone dysplasia characterized by upper limbs rhizomelia and other skeletal anomalies (e.g. short stature, dislocated hips, digitalization of the thumb with bifid distal phalanx), craniofacial features (e.g. microcephaly, large anterior fontanelle, fine and sparse scalp hair, depressed nasal bridge, high arched palate, micrognathia, short neck), congenital heart defects (e.g. pulmonary stenosis), delayed psychomotor development and mild flexion contractures of elbows. Radiologic evaluation may reveal flared epiphyses, platyspondyly and/or digital anomalies. 